\title{
Penilaian Risiko Gangguan Musculoskeletal Disorder Pekerja Batik Dengan Menggunakan Metode Strain index
}

\author{
Dian Palupi Restuputri \\ Teknik Industri, Teknik, Universitas Muhammadiyah Malang \\ Jalan Raya Tlogomas 246 Malang, 0341-464318 \\ Korespondensi penulis, surel: restuputri@gmail.com
}

\begin{abstract}
Workers in batik industry in Indonesia are Very big. The process of batik potentially causes interference in the musculoskeletal system (MSDS). This study aims to analyze employee complaints. Methods using Nordic Body Map questionnaires and work risk analysis on hand with Strain index of batik workers. The result of the research shows that the workers' complaints are upper neck pain and 100\% waist pain, upper arm, and back pain are $87.5 \%$, and pain in the lower part of the neck, left shoulder, right shoulder, upper arm right and right hand is $75 \%$. Based on the risk of work with the strain index method obtained results on Manual Pattern Drawing Posture, Posture Drawing Pattern With Ruler, Posture Batik Pattern, Coloring Posture Batik, Posture Coloring Batik Cap and Posture Washing both right hand and left hand classified the work observed dangerous.
\end{abstract}

Keywords: Nordic Body Map, Job Strain Index, Musculoskeletal Disorders, Batik

\begin{abstract}
Abstrak
Pekerja dalam industri batik di Indonesia sangat besar. Proses membatik berpotensi menimbulkan gangguan pada sistem musculoskeletal (MSDs). Penelitian ini bertujuan untuk melakukan analisis keluhan pekerja. Metode menggunakan kuesioner nordic body map dan analisis risiko kerja pada bagian tangan dengan Strain index pekerja batik tulis. Hasil penelitian didapatkan keluhan pekerja yaitu sakit pada leher bagian atas dan sakit pada pinggang sejumlah 100\%, sakit pada lengan atas bagian kiri dan punggung yaitu sejumlah 87,5\%, dan sakit pada leher bagian bawah, bahu kiri, bahu kanan, lengan atas bagian kanan dan tangan bagian kanan yaitu $75 \%$. Berdasarkan risiko pekerjaan dengan metode strain index didapatkan hasil pada Postur Menggambar Pola Manual, Postur Menggambar Pola Dengan Penggaris, Postur Membatik Pola, Postur Mewarnai Batik tulis, Postur Mewarnai Batik Cap dan Postur Pencucian baik tangan kanan maupun tangan kiri tergolong pekerjaan yang diamati berbahaya.
\end{abstract}

Kata kunci: Nordic Body Map, Job Strain Index, Musculoskeletal Disorders, Batik

\section{Pendahuluan}

Di Indonesia, UKM mempunyai peranan penting dalam pembangunan berkelanjutan [1]. UKM punya sarana penting dalam menyerap tenaga kerja. Kenyataannya, lebih dari $60 \%$ angkatan kerja bekerja di UKM. Namun, UKM masih menghadapi beragam tantangan. Salah satu di antaranya adalah usaha meningkatkan produktivitas, keselamatan dan kesehatan kerja (K3), dan kondisi kerja. Keselamatan dan Kesehatan Kerja (K3) merupakan salah satu aspek penting dalam proses produksi, Untuk itu, penerapan K3 yang efektif dan efisien penting dalam meningkatkan produktifitas dan daya saing UKM di Indonesia. Budaya K3 sangat penting dalam membentuk perilaku pekerja terhadap keselamatan dan kesehatan kerja [2]. K3 di UKM sangat dibutuhkan. Hampir 70\% UKM di indonesia buta K3. Hal ini berdampak pada daya saing produktivitas dari UKM. Salah satunya juga pada industri batik. Batik telah 
ditemukan, diproduksi, dan digunakan di seluruh Indonesia [3]. Indonesia punya lebih dari 48.317 industri batik meliputi industri batik skala besar dan kecil [4]. Berdasarkan data kementerian perdagangan, pekerja industri batik di Indonesia lebih dari 700.000 orang. Industri batik skala kecil menggunakan 792.300 pekerja dan industri batik skala besar mempekerjakan 5.051 orang.

Salah satu keluhan akibat kerja adalah kelainan otot, urat, tulang, sendi, pembuluh darah tepi atau syaraf tepi. Penyakit tersebut disebut Musculoskeletal Disorder (MSDs). MSDs merupakan sekelompok kondisi patologis di mana dapat memengaruhi fungsi normal dari jaringan halus sistem musculoskeletal yang mencakup sistem saraf, tendon, otot dan struktur penunjang bagian tubuh yang menjadi fokus pada penelitian ini adalah punggung dan bahu [5]. Menurut National Institute of Occupational Safety and Health (NIOSH) dan WHO, MSDs merupakan gangguan yang disebabkan seseorang melakukan aktivitas kerja sehingga memengaruhi adanya fungsi normal pada sistem muskuloskeletal yang mencakup saraf, tendon, otot [6]. MSDs umumnya terjadi tidak secara langsung melainkan penumpukan-penumpukan cidera benturan kecil dan besar yang terakumulasi secara terus menerus dalam waktu yang cukup lama yang diakibatkan oleh pengangkatan beban saat bekerja, sehingga menimbulkan cidera dimulai dari rasa sakit, nyeri, pegal-pegal pada anggota tubuh. Musculoskeletal disorders merupakan suatu istilah yang memperlihatkan bahwa adanya gangguan pada sistem musculoskeletal. Selain MSDs. Juga dikenal istilah Work-Related Musculoskeletal Disorders (WMSDs) yang mana merupakan MSDs yang berhubungan dengan pekerjaan. WMSDs dapat diartikan MSDs yang dipengaruhi oleh lingkungan kerja dan performa pekerjaan. WMSDs juga dapat berarti MSDs yang berefek buruk atau dalam waktu lama akan menimbulkan efek buruk yang disebabkan oleh kondisi pekerjaan, karakteristik personal dan factor social yang berkontribusi terhadap perkembangan WMSDs [7]. WMSDs merupakan gangguan yang melibatkan syaraf, otot dan struktur penunjang tubuh sebagai hasil dari aktivitas yang berhubungan dengan pekerjaan [8]. MSDs biasanya tidak hanya disebabkan oleh faktor tunggal sebuah kejadian (seperti jatuh, tergelincir atau tersandung) akan tetapi juga merupakan kombinasi dan akumulasi dari berbagai factor risiko ergonomi dan faktor - faktor lain yang mempengaruhinya.

Batik tulis Sumbersari merupakan industri batik yang terletak di Kabupaten Bondowoso. Batik tulis Sumbersari menerapkan konsep eduwisata Batik yang mana pengunjung dapat belajar tentang batik. Bahkan pengunjung dapat mencoba langsung produksi dari awal sampai akhir. Batik tulis Sumbersari telah berdiri sejak tahun 1985. Beranggotakan perempuan-perempuan karang taruna di desa sumbersari. Kini Batik tulis Sumbersari mempekerjakan 60 masyarakat pengrajin batik. Semua proses di Batik tulis Sumbersari dilakukan secara manual. Salah satu proses dalam membuat batik adalah proses membatik, yang mana proses ini dengan cara menorehkan malam batik ke kain kemudian mengisi pola dengan berbagai macam bentuk dan membuat isian pola yang sudah dibuat dengan memberi titik-titik, yang mana ketika membuat isian pola tersebut tangan pekerja diharuskan menahan kain serta berulang kali mencelupkan canting ke malam untuk mengisi pola tersebut. Proses membatik inilah yang berpotensi menimbulkan gangguan pada sistem musculoskeletal (MSDs).

Sutari, et al. [9] telah melakukan penelitian postur kerja terhadap gangguan kerangka otot pada operator industri batik cap dengan menggunakan RULA. RULA adalah metode dalam penyelidikan berhubungan dengan gangguan ekstremitas pada tubuh bagian atas [10]. Strain index adalah metodologi analisis pekerjaan semi kuantitatif yang mana memberikan analisa dalam bentuk skor angka, skor inilah yang berhubungan dengan risiko kelainan tubuh bagian atas. Enam variable menjelaskan tentang pengerahan tenaga tangan yaitu intensitas penggunaan tenaga, durasi 
penggunaan tenaga, penggunaan tenaga per menit, postur dari tangan atau pergelangan tangan, kecepatan kerja dan durasi kerja per hari [11]. Strain index ini telah digunakan untuk penelitian dengan berbagai bidang khususnya untuk pekerjaan yang berhubungan dengan tangan, misalnya Pabrik pengolahan kalkun [12], Proses pembedahan [13], Pabrik pengolahan babi [14], Sektor manufacturing dan kesehatan [15], Saw-filers [16], Cleaners [17]. Metode ini direkomendasikan untuk pekerjaan repetitive mono task yang mana memungkinkan untuk diobservasi siklus kerjanya per menit [18].

Beberapa penelitian telah banyak dilakukan dalam menilai risiko pekerja. Namun, penelitian untuk menganalisis risiko pekerja batik belum pernah dilakukan khususnya intensitas penggunaan tenaga, durasi penggunaan tenaga, penggunaan tenaga per menit, postur dari tangan atau pergelangan tangan, kecepatan kerja dan durasi kerja per hari. Penelitian ini bertujuan untuk melakukan analisis keluhan pekerja dengan menggunakan kuesioner nordic body map dan analisis risiko kerja pada bagian tangan dengan Strain index pekerja batik tulis. Output dari penelitian ini adalah mengetahui risiko kerja pengrajin batik khususnya pada proses menggambar pola manual, menggambar pola, membatik pola, mewarnai batik cap, dan pencucian.

\section{Metode Penelitian}

Penelitian ini dilaksanakan di Batik tulis Sumbersari. Pemilihan lokasi penelitian berdasarkan pertimbangan Batik tulis Sumbersari telah mengusung konsep eduwisata serta pembuatan batik 3 dimensi secara manual. Batik tulis Sumbersari memiliki 60 karyawan sehingga dibutuhkan analisa mengenai risiko kerja karena pekerjaan dilakukan berulang. Jenis data yang dibutuhkan dalam penelitian ini adalah data primer dan sekunder. Pengumpulan data berdasarkan pengamatan langsung dan wawancara dengan pihak manajemen dan pekerja.

Data primer diperoleh melalui pengamatan secara langsung, observasi dan wawancara kepada karyawan dan beberapa pihak manajemen di batik sumbersari. Adapun data primer yang dibutuhkan dalam penelitian ini meliputi (a) Gambar postur kerja, (b) Kuesioner Nordic Body Map. Data sekunder didapatkan dari arsip-arsip dan dokumen yang berhubungan dengan Batik Sumbersari. Data sekunder yang dibutuhkan dalam penelitian ini meliputi; (a) Profil Perusahaan, (b) Data Pekerja.

Cara yang digunakan untuk memperoleh data primer adalah dengan cara observasi lapangan dan pemberian kuesioner nordic body map [19] kepada pengrajin batik. Kuesioner nordic body map disebarkan ke 50 pekerja batik tulis. Kemudian dilakukan perhitungan persentase keluhan dari pekerja. Berdasarkan persentase keluhan dari pekerja dilakukan pengolahan data menggunakan metode ergonomi yang sesuai yaitu menggunakan strain index [20] sehingga dapat dilakukan analisis dan pembahasan mengenai konsep ergonomic yang akan diaplikasikan guna mengurangi risiko cedera pada para pengrajin batik. Pada penilaian strain index dilakukan untuk postur kerja khususnya pada proses menggambar pola manual, menggambar pola, membatik pola, mewarnai batik cap, dan pencucian.

\section{Hasil dan Pembahasan}

\subsection{Identifikasi Musculoskeletal Disorders (MSDs) dengan Nordic Body Map}

Pada tahap awal dilakukan proses identifikasi MSDs dengan tujuan untuk mengetahui keluhan sakit pada bagian tubuh yang muncul akibat bekerja dengan postur seperti tertera pada tabel. Identifikasi MSDs ini menggunakan Nordic Body Map yang berdasarkan 50 kuesioner yang disebar. 
Tabel 1 memperlihatkan bahwa keluhan yang paling banyak dialami pekerja adalah sakit pada leher bagian atas, pinggang dan kaki. Kemudian jenis keluhan kedua yang terbanyak adalah sakit pada lengan atas dan punggung. Sedangkan jenis keluhan ketiga terbanyak yaitu sakit pada bahu dan tangan. Berdasarkan penilaian keluhan tersebut, peneliti fokus penilaian Strain index untuk postur kerja khususnya pada proses menggambar pola manual, menggambar pola, membatik pola, mewarnai batik cap, dan pencucian.

Tabel 1 Persentase Keluhan Pekerja

\begin{tabular}{cll}
\hline No Pada Nordic Body Map & Jenis Keluhan & Persentase \\
\hline 0 & Sakit pada leher bagian atas & 100 \\
1 & Sakit pada leher bagian bawah & 75 \\
2 & Sakit pada bahu kiri & 75 \\
3 & Sakit pada bahu kanan & 75 \\
4 & Sakit pada lengan atas bagian kiri & 87.5 \\
5 & Sakit pada bagian punggung & 87.5 \\
6 & Sakit pada lengan atas bagian kanan & 75 \\
7 & Sakit pada pinggang & 100 \\
8 & Sakit pada bokong & 62.5 \\
9 & Sakit pada pantat & 50 \\
10 & Sakit pada siku kiri & 25 \\
11 & Sakit pada siku kanan & 25 \\
12 & Sakit pada lengan bawah bagian kiri & 62.5 \\
13 & Sakit pada lengan bawah bagian kanan & 62.5 \\
14 & Sakit pada pergelangan tangan kiri & 50 \\
15 & Sakit pada pergelangan tangan kanan & 37.5 \\
16 & Sakit pada tangan bagian kiri & 62.5 \\
17 & Sakit pada tangan bagian kanan & 75 \\
18 & Sakit pada paha kiri & 25 \\
19 & Sakit pada paha kanan & 25 \\
20 & Sakit pada lutut kiri & 25 \\
\hline
\end{tabular}

\subsection{Penilaian Postur Kerja menggunakan Job Strain Index}

\subsubsection{Postur Menggambar Pola Manual}

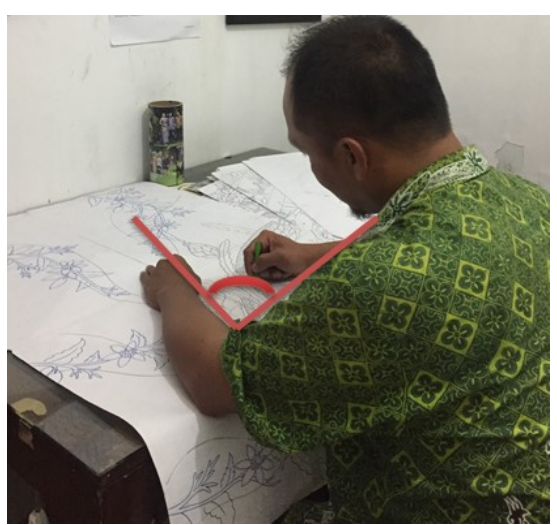

Gambar 1 Menggambar Pola Manual

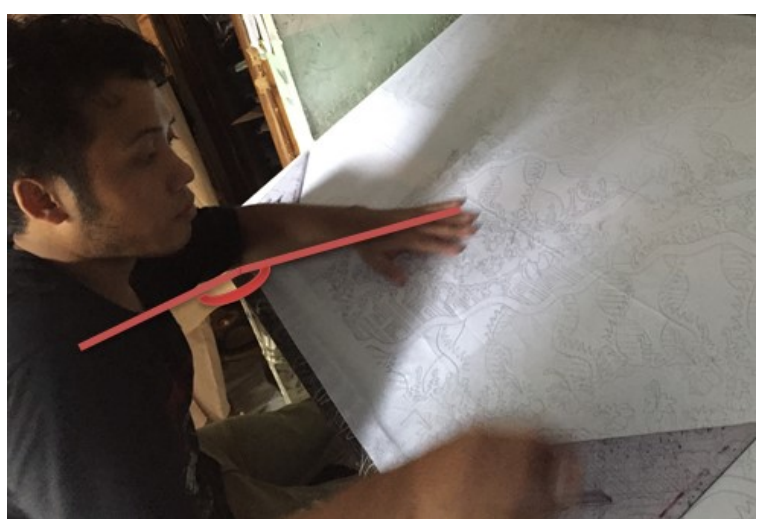

Gambar 2 Postur Menggambar Pola 
Tabel 2 Tabel Rekapitulasi JSI Menggambar Pola Manual Untuk Tangan Kanan dan kiri

\begin{tabular}{|c|c|c|c|}
\hline Pemeriksaan & Langkah & Keterangan & Rating \\
\hline \multirow[t]{6}{*}{ Tangan Kanan } & Intensity of Exertion (IE) & light & 1 \\
\hline & $\begin{array}{l}\text { Duration of Exertion } \\
(D E)\end{array}$ & $80-100 \%$ & 3 \\
\hline & Effort/Minute (EM) & $>=20$ & 3 \\
\hline & $\begin{array}{l}\text { Hand and Wrist Posture } \\
(H W P)\end{array}$ & Very Bad & 3 \\
\hline & Speed of Work (SW) & Slow & 1 \\
\hline & Duration Per Day (DD) & $>=8$ & 1,5 \\
\hline \multirow[t]{6}{*}{ Tangan Kiri } & Intensity of Exertion (IE) & Light & 1 \\
\hline & $\begin{array}{l}\text { Duration of Exertion } \\
(D E)\end{array}$ & $<10 \%$ & 0,5 \\
\hline & Effort/Minute (EM) & $<4(0,5)$ & 0,5 \\
\hline & $\begin{array}{l}\text { Hand and Wrist Posture } \\
(H W P)\end{array}$ & Very Bad & 3 \\
\hline & Speed of Work (SW) & Very Slow & 1 \\
\hline & Duration Per Day (DD) & $>=8$ & 1,5 \\
\hline
\end{tabular}

Berdasarkan Gambar 1, Intensity of Exertion (IE) diperoleh dari skala BORG. Nilai tangan kanan dan kiri skala BORG $<2$. menunjukkan bahwa aktivitas tersebut dapat dikategorikan sebagai pekerjaan ringan dengan persentase kekuatan maksimal 10\%. Sehingga untuk Intensity of Exertion (IE) mendapatkan nilai rating 1. Berdasarkan hasil perhitungan nilai Duration of Exertion (DE) tangan kanan sebesar 87,5\% dan 9\% untuk tangan kiri. sehingga untuk durasi usaha mendapatkan nilai rating tangan kanan sebesar 3 dan 0,5 untuk tangan kiri. Perhitungan usaha per menit (Effort per Minute/EM) sebesar 30 kali untuk tangan kanan dan 0 untuk tangan kiri. Sehingga untuk usaha per menit mendapatkan nilai rating 3 untuk tangan kanan dan 0,5 untuk tangan kiri. Posisi Tangan/Pergelangan Tangan (Hand/Wrist Posture/HWP) kanan dan kiri pada saat melakukan aktivitas menggambar pola yaitu ulnar deviation membentuk sudut $30 \%$ dan $45 \%$ dengan kategori di kedua tangan Very Bad. sehingga untuk posisi tangan/pergelangan tangan mendapatkan nilai rating 3. Kecepatan Kerja (Speed of Work/SW) Kecepatan kerja sebesar $85 \%$ dengan rating Slow dengan rating 1. Durasi Kerja per Hari (Duration of Task per Day/DD hari bekerja selama 8 jam dengan rating 1,5. Rekapitulasi JSI Menggambar Pola Manual Untuk Tangan Kanan dan kiri dapat dilihat pada Tabel 2. Rekapitulasi hasil perhitungan skor SI pada aktivitas kerja menggambar pola ditunjukkan pada Tabel 3.

Tabel 3 Job Strain Indeks Worksheet Menggambar Pola Manual

\begin{tabular}{|c|c|c|c|c|c|c|c|c|c|}
\hline \multirow{2}{*}{\multicolumn{2}{|c|}{ Risk Factor }} & \multicolumn{6}{|c|}{ Menggambar Pola Manual } & \multirow{2}{*}{ Nilai JSI } & \multirow{2}{*}{$\begin{array}{c}\text { Kategori } \\
\text { Pekerjaan }\end{array}$} \\
\hline & & IE & $\mathrm{DE}$ & EM & HWP & SW & DD & & \\
\hline \multirow{2}{*}{$\mathrm{X} 1$} & Kanan & 1 & 3 & 3 & 3 & 1 & 1,5 & 40,5 & Hazardous \\
\hline & Kiri & 1 & 0,5 & 0,5 & 3 & 1 & 1,5 & 1,25 & Safe \\
\hline
\end{tabular}




\subsubsection{Postur Menggambar Pola}

Posisi pekerja dengan postur menggambar pola dapat dilihat pada Gambar 2. Berdasar tabel rekapitulasi Job Strain index pada Tabel 4 dan Tabel 5 dapat disimpulkan bahwa nilai JSI 9 yang berarti pekerjaan tersebut berada pada level hazardous atau berisiko tinggi.

Tabel 4 Tabel Rekapitulasi JSI Postur Menggambar Pola Untuk Tangan Kanan dan Tangan Kiri

\begin{tabular}{|c|c|c|c|}
\hline Pemeriksaan & Langkah & Keterangan & Rating \\
\hline \multirow[t]{6}{*}{ Tangan Kanan } & Intensity of Exertion (IE) & Somewhat Hard & 3 \\
\hline & $\begin{array}{l}\text { Duration of Exertion } \\
(D E)\end{array}$ & $50-70 \%$ & 2 \\
\hline & Effort/Minute (EM) & $>=20$ & 3 \\
\hline & $\begin{array}{l}\text { Hand and Wrist Posture } \\
(H W P)\end{array}$ & Fair & 1,5 \\
\hline & Speed of Work (SW) & Very Slow & 1 \\
\hline & Duration Per Day (DD) & $4-8$ & 1 \\
\hline \multirow[t]{6}{*}{ Tangan Kiri } & Intensity of Exertion (IE) & Light & 1 \\
\hline & $\begin{array}{l}\text { Duration of Exertion } \\
(D E)\end{array}$ & $50-70 \%$ & 2 \\
\hline & Effort/Minute (EM) & $>=20$ & 3 \\
\hline & $\begin{array}{l}\text { Hand and Wrist Posture } \\
(H W P)\end{array}$ & Fair & 1,5 \\
\hline & Speed of Work (SW) & Very Slow & 1 \\
\hline & Duration Per Day (DD) & $4-8$ & 1 \\
\hline
\end{tabular}

Tabel 5 Job Strain Indeks Worksheet Postur Menggambar Pola

\begin{tabular}{|c|c|c|c|c|c|c|c|c|c|}
\hline \multirow{2}{*}{\multicolumn{2}{|c|}{ Risk Factor }} & \multicolumn{6}{|c|}{ Postur Menggambar Pola } & \multirow{2}{*}{ Nilai JSI } & \multirow{2}{*}{$\begin{array}{c}\text { Kategori } \\
\text { Pekerjaan }\end{array}$} \\
\hline & & $\mathrm{IE}$ & $\mathrm{DE}$ & EM & HWP & SW & DD & & \\
\hline \multirow{2}{*}{$\mathrm{X} 1$} & Kanan & 3 & 2 & 3 & 1,5 & 1 & 1 & 9 & Hazardous \\
\hline & Kiri & 1 & 2 & 3 & 1,5 & 1 & 1 & 9 & Hazardous \\
\hline
\end{tabular}

\subsubsection{Postur Membatik Pola}

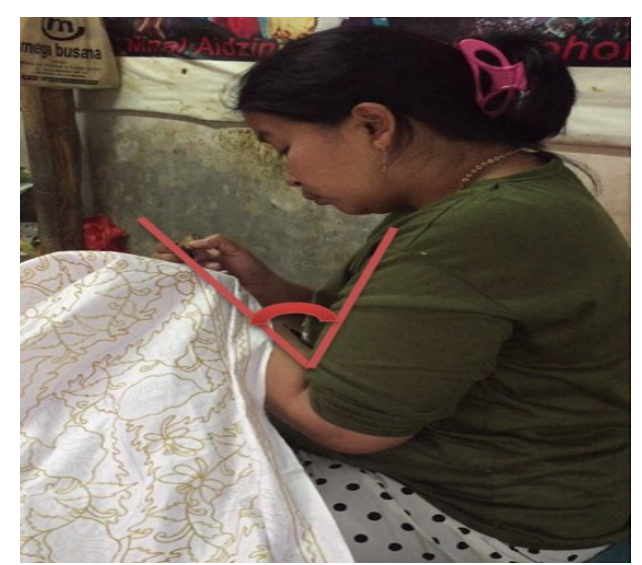

Gambar 3 Postur Membatik Pola

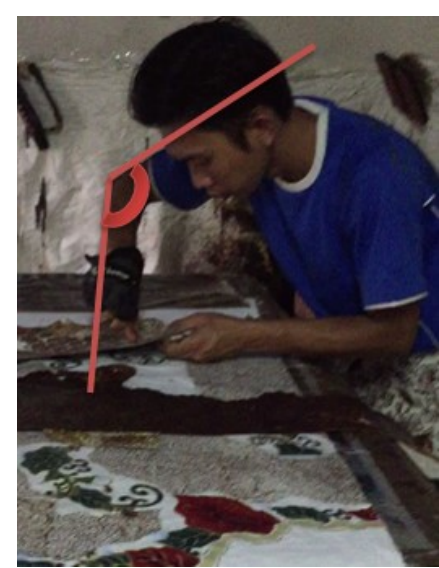

Gambar 4 Postur Mewarnai Batik Cap 
Posisi pekerja dengan postur membatik pola dapat dilihat pada Gambar 3. Berdasar tabel rekapitulasi Job Strain index pada Tabel 6 dan Tabel 7 dapat disimpulkan bahwa nilai JSI 9 yang berarti pekerjaan tersebut berada pada level hazardous atau berisiko tinggi.

Tabel 6 Tabel Rekapitulasi JSI Membatik Pola Untuk Tangan Kanan dan Tangan Kiri

\begin{tabular}{cllc}
\hline Pemeriksaan & \multicolumn{1}{c}{ Langkah } & Keterangan & Rating \\
\hline Tangan Kanan & $\begin{array}{l}\text { Intensity of Exertion (IE) } \\
\text { Duration of Exertion } \\
\text { (DE) }\end{array}$ & Very Hard & 9 \\
& $\begin{array}{l}\text { Effort/Minute (EM) } \\
\text { Hand and Wrist Posture }\end{array}$ & $>=20$ & Bad \\
& $\begin{array}{l}\text { (HWP) } \\
\text { Speed of Work (SW) }\end{array}$ & Fair & 2 \\
& Duration Per Day (DD) & $4-8$ & 3 \\
Tangan Kiri & $\begin{array}{l}\text { Intensity of Exertion (IE) } \\
\text { Duration of Exertion Hard }\end{array}$ & $50-70 \%$ & 2 \\
& $\begin{array}{l}\text { (DE) } \\
\text { Effort/Minute (EM) }\end{array}$ & $>=20$ & 1 \\
& $\begin{array}{l}\text { Hand and Wrist Posture } \\
\text { (HWP) }\end{array}$ & Fair & 1 \\
\hline Speed of Work (SW) & Fair & 2 \\
Duration Per Day (DD) & $4-8$ & 3 \\
& & & 1,5 \\
\hline
\end{tabular}

Tabel 7 Job Strain Indeks Worksheet Membatik Pola

\begin{tabular}{|c|c|c|c|c|c|c|c|c|c|}
\hline \multirow{2}{*}{\multicolumn{2}{|c|}{ Risk Factor }} & \multicolumn{6}{|c|}{ Membatik Pola } & \multirow{2}{*}{ Nilai JSI } & \multirow{2}{*}{$\begin{array}{c}\text { Kategori } \\
\text { Pekerjaan }\end{array}$} \\
\hline & & $\mathrm{IE}$ & $\mathrm{DE}$ & EM & HWP & SW & DD & & \\
\hline \multirow{2}{*}{$\mathrm{X} 1$} & Kanan & 9 & 2 & 3 & 2 & 1 & 1 & 108 & Hazardous \\
\hline & Kiri & 9 & 2 & 3 & 1,5 & 1 & 1 & 81 & Hazardous \\
\hline
\end{tabular}

\subsubsection{Postur Mewarnai Batik Cap}

Posisi pekerja dengan postur mewarnai batik cap dapat dilihat pada Gambar 4. Berdasar tabel rekapitulasi Job Strain index pada

Tabel 8 dan Tabel 9 dapat disimpulkan bahwa nilai JSI 9 yang berarti pekerjaan tersebut berada pada level hazardous atau berisiko tinggi.

\subsubsection{Postur Pencucian}

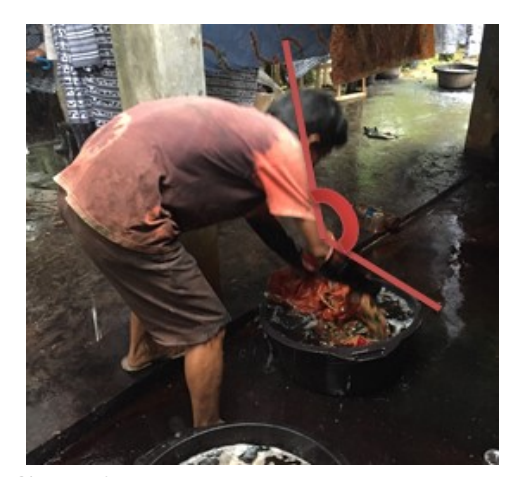

Gambar 5 Postur Pencucian 
Tabel 8 Rekapitulasi JSI Mewarnai Batik Cap Untuk Tangan Kanan dan Tangan Kiri

\begin{tabular}{|c|c|c|c|}
\hline Pemeriksaan & Langkah & Keterangan & Rating \\
\hline \multirow[t]{6}{*}{ Tangan Kanan } & Intensity of Exertion (IE) & Near Maximal & 15 \\
\hline & $\begin{array}{l}\text { Duration of Exertion } \\
(D E)\end{array}$ & $50-70 \%$ & 2 \\
\hline & Effort/Minute (EM) & $9-14$ & 1,5 \\
\hline & $\begin{array}{l}\text { Hand and Wrist Posture } \\
(H W P)\end{array}$ & $\mathrm{Bad}$ & 2 \\
\hline & Speed of Work (SW) & Fair & 1 \\
\hline & Duration Per Day (DD) & $4-8$ & 1 \\
\hline \multirow[t]{6}{*}{ Tangan Kiri } & Intensity of Exertion (IE) & Very Hard & 9 \\
\hline & $\begin{array}{l}\text { Duration of Exertion } \\
(D E)\end{array}$ & $50-70 \%$ & 2 \\
\hline & Effort/Minute (EM) & $4-8$ & 1 \\
\hline & $\begin{array}{l}\text { Hand and Wrist Posture } \\
(H W P)\end{array}$ & Fair & 1,5 \\
\hline & Speed of Work (SW) & Fair & 1 \\
\hline & Duration Per Day (DD) & $4-8$ & 1 \\
\hline
\end{tabular}

Tabel 9 Job Strain Indeks Worksheet Mewarnai Batik Cap

\begin{tabular}{|c|c|c|c|c|c|c|c|c|c|}
\hline \multirow{2}{*}{\multicolumn{2}{|c|}{ Risk Factor }} & \multicolumn{6}{|c|}{ Mewarnai Batik Cap } & \multirow{2}{*}{ Nilai JSI } & \multirow{2}{*}{$\begin{array}{l}\text { Kategori } \\
\text { Pekerjaan }\end{array}$} \\
\hline & & $\mathrm{IE}$ & $\mathrm{DE}$ & EM & HWP & SW & $\mathrm{DD}$ & & \\
\hline \multirow{2}{*}{$\mathrm{X} 1$} & Kanan & 13 & 2 & 1,5 & 2 & 1 & 1 & 78 & Hazardous \\
\hline & Kiri & 9 & 2 & 1 & 1,5 & 1 & 1 & 27 & Hazardous \\
\hline
\end{tabular}

Posisi pekerja dengan postur pencucian dapat dilihat pada Gambar 5. Berdasar tabel rekapitulasi Job Strain index pada Tabel 10 dan Tabel 11 dapat disimpulkan bahwa nilai JSI 9 yang berarti pekerjaan tersebut berada pada level hazardous atau berisiko tinggi.

\section{Simpulan}

Berdasar hasil kuesioner nordic body map didapatkan urutan keluhan pekerja yaitu sakit pada leher bagian atas dan sakit pada pinggang sejumlah $100 \%$, sakit pada lengan atas bagian kiri dan punggung yaitu sejumlah $87,5 \%$, dan sakit pada leher bagian bawah, bahu kiri, bahu kanan, lengan atas bagian kanan dan tangan bagian kanan yaitu 75\%. Penggunaan metode strain index pada pekerja batik didapatkan hasil yaitu pada Postur Menggambar Pola Manual, Postur Menggambar Pola, Postur Membatik Pola, Postur Mewarnai Batik tulis, Postur Mewarnai Batik Cap dan Postur Pencucian baik tangan kanan maupun tangan kiri tergolong pekerjaan yang diamati cukup berbahaya kecuali postur pola menggambar manual untuk tangan kiri tergolong pekerjaan yang cukup aman. Penelitian selanjutnya dapat membuat alat bantu untuk para pekerja untuk meminimasi bahaya pada pekerja. 
Tabel 10 Rekapitulasi JSI Pencucian Untuk Tangan Kanan dan Tangan Kiri

\begin{tabular}{|c|c|c|c|}
\hline Pemeriksaan & Langkah & Keterangan & Rating \\
\hline \multirow[t]{6}{*}{ Tangan Kanan } & $\begin{array}{l}\text { Intensity of Exertion } \\
\text { (IE) }\end{array}$ & Near Maximal & 15 \\
\hline & $\begin{array}{l}\text { Duration of Exertion } \\
(D E)\end{array}$ & $50-70 \%$ & 2 \\
\hline & Effort/Minute (EM) & $9-14$ & 1,5 \\
\hline & $\begin{array}{l}\text { Hand and Wrist Posture } \\
(H W P)\end{array}$ & Very Bad & 3 \\
\hline & Speed of Work (SW) & Fair & 1 \\
\hline & Duration Per Day (DD) & $4-8$ & 1 \\
\hline \multirow[t]{6}{*}{ Tangan Kiri } & $\begin{array}{l}\text { Intensity of Exertion } \\
\text { (IE) }\end{array}$ & Near Maximal & 15 \\
\hline & $\begin{array}{l}\text { Duration of Exertion } \\
(D E)\end{array}$ & $50-70 \%$ & 2 \\
\hline & Effort/Minute (EM) & $9-14$ & 1,5 \\
\hline & $\begin{array}{l}\text { Hand and Wrist Posture } \\
(H W P)\end{array}$ & Very Bad & 3 \\
\hline & Speed of Work (SW) & Fair & 1 \\
\hline & Duration Per Day (DD) & $4-8$ & 1 \\
\hline
\end{tabular}

Tabel 11 Job Strain Indeks Worksheet Pencucian

\begin{tabular}{cccccccccc}
\hline \multirow{2}{*}{ Risk Factor } & \multicolumn{7}{c}{ Pencucian } & \multirow{2}{*}{ Nilai JSI } & $\begin{array}{c}\text { Kategori } \\
\text { Pekerjaan }\end{array}$ \\
\cline { 3 - 9 } & IE & DE & EM & HWP & SW & DD & & Kanan \\
\cline { 2 - 9 } & 13 & 2 & 1,5 & 3 & 1 & 1 & 117 & Hazardous \\
& Kiri & 13 & 2 & 1,5 & 3 & 1 & 1 & 117 & Hazardous \\
\hline
\end{tabular}

\section{Referensi}

[1] S. Wahyuningsih, "Peranan UKM Dalam Perekonomian Indonesia," MEDIAGRO, vol. 5, 2009.

[2] W. Y. Christina, L. Djakfar, and A. Thoyib, "Pengaruh Budaya Keselamatan dan Kesehatan Kerja (K3) terhadap kinerja proyek konstruksi," Rekayasa Sipil, vol. 6, pp. 83-95, 2012.

[3] K. Saddhono, S. T. Widodo, M. T. Al-Makmun, and M. Tozu, "The study of philosophical meaning of batik and kimono motifs to foster collaborative creative industry," Asian Social Science, vol. 10, p. 52, 2014.

[4] R. A. Anugraha, W. Sutan, and I. Mufidah, "The design of batik stamp tool scraping working table using ergonomics principles," Procedia Manufacturing, vol. 4, pp. 543-551, 2015.

[5] L. Punnett and D. H. Wegman, "Work-related musculoskeletal disorders: the epidemiologic evidence and the debate," Journal of electromyography and kinesiology, vol. 14, pp. 13-23, 2004.

[6] S. L. Sauter, L. R. Murphy, and J. J. Hurrell, "Prevention of work-related psychological disorders: A national strategy proposed by the National Institute for Occupational Safety and Health (NIOSH)," American Psychologist, vol. 45, p. 1146, 1990. 
[7] K. G. Davis and L. Orta Anés, "Potential of adjustable height carts in reducing the risk of low back injury in grocery stockers," Applied Ergonomics, vol. 45, pp. 285292, 2014/03/01/ 2014.

[8] B. P. Bernard and V. Putz-Anderson, "Musculoskeletal disorders and workplace factors; a critical review of epidemiologic evidence for work-related musculoskeletal disorders of the neck, upper extremity, and low back," 1997.

[9] W. Sutari, Y. N. D. Yekti, and M. D. Astuti, "Analysis of working posture on muscular skeleton disorders of operator in stamp scraping in "batik cap'industry," Procedia Manufacturing, vol. 4, pp. 133-138, 2015.

[10] F. Abdillah, "Analisis postur kerja dengan metode Rapid Upper Limb Assesment (RULA) pada pekerja kuli angkut buah di Agen Ridho Illahi Pasar Johar Kota Semarang," Jurnal Kesehatan Masyarakat Universitas Diponegoro, vol. 2, 2013.

[11] M.-È. Chiasson, D. Imbeau, K. Aubry, and A. Delisle, "Comparing the results of eight methods used to evaluate Risk Factors associated with musculoskeletal disorders," International Journal of Industrial Ergonomics, vol. 42, pp. 478-488, 2012.

[12] K. Knox and J. S. Moore, "Predictive validity of the Strain index in turkey processing," Journal of occupational and environmental medicine, vol. 43, pp. 451462, 2001.

[13] E. Lee, A. Rafiq, R. Merrell, R. Ackerman, and J. Dennerlein, "Ergonomics and human factors in endoscopic surgery: a comparison of manual vs telerobotic simulation systems," Surgical endoscopy and other interventional techniques, vol. 19, pp. 1064-1070, 2005.

[14] N. Rucker and J. S. Moore, "Predictive validity of the strain index in manufacturing facilities," Applied occupational and environmental hygiene, vol. 17, pp. 63-73, 2002.

[15] S. Bao, N. Howard, P. Spielholz, and B. Silverstein, "Quantifying repetitive hand activity for epidemiological research on musculoskeletal disorders-Part II: comparison of different methods of measuring force level and repetitiveness," Ergonomics, vol. 49, pp. 381-392, 2006.

[16] T. Jones and S. Kumar, "Comparison of ergonomic risk assessments in a repetitive high-risk sawmill occupation: Saw-filer," International Journal of Industrial Ergonomics, vol. 37, pp. 744-753, 2007.

[17] J. M. Cabeças, "The risk of distal upper limb disorder in cleaners: A modified application of the Strain index method," International journal of industrial ergonomics, vol. 37, pp. 563-571, 2007.

[18] S. Bao, P. Spielholz, N. Howard, and B. Silverstein, "Application of the Strain index in multiple task jobs," Applied Ergonomics, vol. 40, pp. 56-68, 2009.

[19] J. O. Crawford, "The Nordic musculoskeletal questionnaire," Occupational medicine, vol. 57, pp. 300-301, 2007.

[20] J. Steven Moore and A. Garg, "The strain index: a proposed method to analyze jobs for risk of distal upper extremity disorders," American Industrial Hygiene Association Journal, vol. 56, pp. 443-458, 1995. 